\title{
Teacher Professional Development as a Catalyst for Faculty Development: The Case of a University in China
}

\author{
Michael Agyemang Adarkwah ${ }^{1}$, Yohana Kifle Mekonen ${ }^{1}$, Usama Kalim ${ }^{1}$ \\ ${ }^{1}$ Southwest University, China \\ Correspondence: PhD(c), Michael Agyemang Adarkwah, Faculty of Education, Southwest University, Tianzhu Street, \\ Beibei District, Chongqing, Southwest University, No. 2, China.
}

Received: January 24, 2021

doi:10.11114/jets.v9i5.5139

\author{
Accepted: April 23, 2021 \\ Online Published: April 27, 2021 \\ URL: https://doi.org/10.11114/jets.v9i5.5139
}

\begin{abstract}
Teacher professional development (TPD) is integral for faculty development through quality teacher performances and student outcomes. Prior research on TPD indicates that school leaders at the helm of educational affairs are responsible for implementing and sustaining TPD activities for better school improvement. In the higher education (HE) context, fewer research studies have been conducted on TPD. Most HE institutions still struggle to implement, sustain, and improve TPD in China and significant parts of the world. The qualitative research utilized a case study approach to solicit information from two deans of a selected university faculty in China reputable for its TPD programs. The three key leadership practices explored in this study were; how leadership support TPD, the role of TPD in faculty development, and the challenges of TPD in the HE context. Findings from the study indicate that China's hierarchical structure has positively affected TPD programs in this university due to the Chinese culture and tradition. Clear and concrete policies emerged as an essential step towards TPD implementation. Motivational strategies such as incentives and academic conferences have been identified as integral factors for TPD sustainability. Also, mentorship and collaboration among teachers and other stakeholders were integral to enhancing teachers' research capacity. Educators should ensure the evaluation and supervision of TPD for it to achieve its intended goals.
\end{abstract}

Keywords: teacher professional development, leadership, faculty development, higher education, continuing professional development

\section{Introduction}

In recent years, Teacher Professional Development (TPD) is widely accepted as instrumental in enhancing teacher improvement for students' higher academic achievement (Szetoa, Sin, \& Leung, 2020; Trent, 2020; West \& Bautista, 2020). Effective TPD has become an international concern (Avidov-Ungar \& Ezran, 2018). Teachers play a vital role in students' education (Keller, Neumann, \& Fischer, 2017; Morris \& Patterson, 2013). Effective TPD is necessary for teachers to learn and refine the pedagogies needed to properly instruct students (Darling-Hammond, Hyler, Gardner, \& Espinoza, 2017). TPD is defined as the process of rapidly enhancing professional attainment, widening academic knowledge, improving professional skills, and teacher ability (Ji \& Cao, 2016; Zhao, 2010). TPD focuses on modelling effective pedagogy and content knowledge (Falkner, Vivian, \& Williams, 2018). That includes workshops, coaching, and frequent teaching practices that foster teacher skills and knowledge for student improvement and development (Hanno \& Gonzalez, 2019). High-quality TPD can equip teachers with knowledge and skills that result in a change in their attitudes and beliefs, which ultimately positively impacts students' outcomes (Didion, Toste, \&Filderman, 2019). Trent (2020) perceives TPD as a complex concept because it can be seen as any activity oriented towards bringing a positive change in teacher competence. According to the researcher, the increasing mobility of students and teachers call for the internalization of TPD where international teaching experiences and taught overseas courses are incorporated in the education of both pre-service and in-service teachers. However, in-service teacher education in mainland China has been criticized for failing to improve teaching skills and the academic performance of students. Ji \& Cao (2016) posited that teachers in China were 12 million as of 2016, and all teachers in China are required to partake in 240 hours of TPD programs every five years. They mentioned that although teachers are to engage in TPD programs, they face challenges such as inadequate resources, time conflict, and bad organization. Zhao (2010) also found that the failure of TPD in some schools in China is because of inadequate resources available for teachers. 
Higher education (HE) institutions are enormous, complex, dynamic social systems confronted with numerous challenges and threats that affect education and lead to many uncertainties among educators (Brancato, 2003; Yue, Chen, Wang, \& Liu, 2017). These challenges have impacted the process of teaching and learning over the last decade across the world (Sarker, Davis, \&Tiropanis, 2010). Hence, "societal expectations and public resources for higher education are undergoing fundamental shifts. Changes both within and outside the academy are altering its character - its students, faculty, governance, curriculum, functions, and every place in society" (Zusman, 2005 p.5). In response, there has been increasing recognition for the significance of Continuing Professional Development (CPD) of academicians as a learning community of intellectuals expecting to adapt to the current century's demands (Elton, 2009). According to Stefani, \& Elton, (2002, p.117) "CPD for academics is a special case of CPD in general, which in turn is a special case of the education of adults" that arises from the practical practices as the world is changing continuously due to globalization (Nappi, 2014). Thus, a change in students' demands and learning styles equally demands teachers to move at a similar pace. The higher educational requirement, increased number of overseas students, and digital technology connection requires new and updated educational standards (Yue, Chen, Wang, \& Liu, 2017). As a result, many researchers supported the significant role of professional development for lecturers and tutors in higher institutions to respond to students' needs (Wood,.et al,2011; Antil, 2017). However, limited studies have explored several factors and challenges related to the effectiveness of PD programs (Geijsel et al., 2009; Evers et al., 2011; Marti \& Ferrer, 2012; Noe et al., 2013).

\subsection{Background Context}

Over the years, TPD has become integral in Chinese institutions due to the extensive curriculum reform in the school context (Wang, 2012). Most TPD activities in China focus on how teachers would acquire 21st-century skills necessary for teaching and learning (Kayange \& Msiska, 2016). Teachers in China must engage in research-oriented TPD programs (Wang, Lavonen \& Tirri, 2018). The government plays a significant role in TPD through policies and incentives to attract teachers and increase their participation in TPD programs (OECD, 2016; Zhu \& Han, 2006). Some of the TPD programs for Chinese teachers include school-universities partnership, collaborative lesson planning, sharing sessions on teaching and learning techniques, exchange programs, peer coaching, and self-directed TPD activities such as research publication, action research, and reflection (Guo, 2012; Lam, 2015, Zhao, 2013; Zhou, 2014). Nevertheless, TPD in Chinese institutions is not free from criticisms (Ji \& Cao, 2016; Trent, 2020). The major challenge associated with collaborative TPD in Shangai (China) and England schools was identified as policies by school educators that emphasize teacher appraisal and measurement of students' learning outcomes (Yan Zeng \& Day, 2019). Policies like these tend to make teachers focus on the classroom instead of their PD. Leadership practices affect TPD (Hallinger, Liu, \& Piyaman, 2017; Somprach, Tang, \& Popoonsak, 2017). A study that examined TPD in rural China revealed that school leaders used a weaker learning-centered leadership form (Liu \& Hallinger, 2018).

The university selected for the study is located in Chongqing, and is currently ranked 60 in China (Unirank, 2019). Formed in 2005, it has over 45,000 students and provides diverse Chinese and English courses that are recognized internationally. The Faculty of Education of the selected university is one of the leading faculties of education in China. Currently, it is the third (3rd) best faculty of education in China. The faculty provides $17 \mathrm{PhD}$ courses, 17 master's degree programs, and 3 bachelor's degree programs. One of its English taught courses won the National Brand Course for international students after its establishment in 2013. In 2018, one of its programs won the "CSC 2018-2019 Postgraduates program," which means scholarships and grants are available for students who pursue the program. Preliminary data reveals the dramatic rise of the faculty to its recent prestigious position in China. Given that many schools and faculties strive to attain excellence and the position held by the Faculty of Education of selected university, the faculty has been taken as a case study to explore the leadership practices on teacher professional development, which is an important factor considered to have led to the improvement of the faculty. The findings will serve as a precedent for schools striving to attain such a feat. Educators and school leaders will also benefit from successfully implementing TPD programs in their school to ensure continuous learning and school improvement.

\subsection{The Research Gap of Leadership Practices on TPD in Higher Education}

Traditionally, studies conducted on TPD focus on pre-tertiary education context. Studies found on TPD in China investigated the subject in pre-school or secondary school context (He \& Ho, 2016; Li, Hallinger, \& Walker, 2015; Lijuan \& Hallinger, 2016; Liu \&Hallinger, 2018; Ke, Yin, \& Huang, 2019). Few studies have investigated TPD in higher education. Also, the majority of studies on TPD in HE are conducted using the quantitative approach, which deprives school leaders and teachers from allowing their voices to be heard. For example, Razzak (2013) investigated the effectiveness of university-based PD on school leaders' management and competencies in implementing PD and ICT integration using a quantitative approach. The studies did not highlight on how TPD is implemented and how leaders support TPD in their universities. The systematic review by Gast et al. (2017) on team-based PD interventions in HE only focused on the aspect of collaboration between teachers in PD activities with little emphasis on implementing collaborative PD activities for teachers and how leaders provide support for teachers to encourage collaboration in TPD 
programs. To fill the gap in prior research studies, this study takes a fresh look at TPD in the HE context while considering the essential role of school leaders. Leadership practices have the potential to facilitate or hinder effective TPD. The findings of the study derived from answers to the research questions can give an in-depth understanding of how school leaders ensure successful TPD programs for faculty development. The paper is one of the few studies that argues that context-based TPD is essential for faculty development. Thus, context is necessary in the debate on centralization and decentralization of professional development programs in higher education.

\subsection{Purpose of the Study}

TPD has been essential in educational reform, and school leaders can influence the implementation of principles that affect teacher quality and professional development (Bredeson, 2000; Yager\&Yager, 2011). The connection between TPD and leadership practices is supported by literature (Mourão, 2018). Effective leaders provide diverse professional development (PD) programs for their teachers to enhance their knowledge and skills in terms of resources, human, time, material, and finances (Xin \& Dervin, 2014). Researchers have identified professional learning (development) of teachers as a path through which school leadership can improve the learning of students. Hence, a recent study focused on how school leaders can engage and motivate teachers in professional development activities (Hallinger, Liu, \& Piyaman, 2017). Studying TPD in HE is very important because there is less research on TPD activities in higher education in China. TPD in HE is different from TPD in pre-tertiary education (Gast, Schildkamp, \& van der Veen, 2017), and school leadership practices in promoting TPD in China is different from the Western context because of social culture and hierarchical system (He \& Ho, 2017).

The purpose of this study conducted in a university in China seeks to explore leadership practices towards TPD activities for faculty development in the context of HE. The limited studies on TPD in HE, the notion that TPD implementation and sustenance in HE in China and beyond has failed to achieve its objectives, coupled with the successful TPD program in the selected university led to the following research questions that guided the study;

RQ1. What leadership support was provided for the implementation of TPD?

RQ2. What role has TPD played in facilitating faculty development?

RQ3. What are the perceived challenges associated with TPD in higher education?

\section{Literature Review}

\subsection{Leadership Support for TPD}

School leadership, regardless of the leadership style (autocratic, transformational, instructional, or transactional), play an essential role in the implementation and success of TPD (Evers, Van der Heijden, \& Kreijns, 2016; Hallinger \& Liu, 2017; He \& Ho, 2017). Leadership and supervision is an integral facilitating factor for professional communities (Gast, Schildkamp, \& van der Veen, 2017). The provision of school-based TPD is a core practice through which school administrators can exercise leadership to build a school's capacity and promote student learning (He \& Ho, 2016). Effective support and participation from school leaders for TPD is the most important factor through which school leaders can impact student learning, outcomes, and improvement (Robinson, Lloyd, \& Rowe, 2008). School leaders' commitment to TPD increases teacher engagement in PD activities (Matsumura, Sartoris, Bickel, \& Garnier, 2009). Fancera (2019) believes school leaders' support and promotion for the delivery of TPD programs should focus on teacher growth to accomplish educational objectives set for a school. In a research conducted in China, school leader support was identified as positively impacting school-based TPD (Ke, Yin, \& Huang, 2019). The support that can be provided by school administrators for TPD activities includes funding costs incurred by teachers, providing teachers with salary incentives, providing teachers with opportunities for promotion and salary progression, long-time commitment for TPD, and provision of resources and time (Badri, Alnuaimi, Mohaidat, Yang, \& Rashedi, 2016).

Organizational factors are crucial to TPD. School leaders should provide teachers with organizational facilities such as training centers and courses, and social networks (Evers, van der Heijden, Kreijns, \& Gerrichhauzen, 2011). According to the authors, school leaders should provide instrumental (support to complete a task), emotional (health support to improve self-esteem), appraisal (information necessary for self-evaluation), and informational support (support that helps the individuals to help themselves). In China, school leaders play a pragmatic role in TPD to ensure diverse students' learning (Szeto, 2020). In Turkey, it was found out that school administrators supported TPD activities the most by informing teachers of recent innovations in the field of education and the least by teaching a sample class to professionally develop teachers (Öğretmen, Gelişimine, \& Algıları, 2020). The author opined that since teachers' lesson notes have an influence in the learning of students, it is imperative for the administrators to have access to relevant academic resources which they can use to improve teachers professionally. In Vietnam, school leaders provided support for TPD activities by creating four working conditions; collaboration between teachers, empowering teachers, supervising and evaluating teachers (Tran, et al., 2020). The collaboration was ensured by providing opportunities for teachers to have meetings on 
professional issues that improve teachers' teaching and learning. Teachers were empowered by giving them opportunities to participate in decision making during seminars and weekly professional meetings and through mentoring, peer coaching, and self-learning. Supervision and evaluation of TPD activities were frequent to improve the instructional performance of teachers. Some of the motivational strategies adopted to improve the teachers professionally included rewards and punishment, recognition, regulation and policies. In Singapore, the support provided by school leaders, such as the provision of resources for TPD activities, is geared towards bringing about teacher-initiated innovation and curricular development in order to develop and ensure the high academic performance of students (Hairon \& Dimmock, 2012). Supportive and shared leadership is required to facilitate TPD to promote teaching and learning ( $\mathrm{Li}$, Hallinger, \& Walker, 2015).

\subsection{Role of TPD in Facilitating Faculty Development}

Educational success depends on efficient teachers, which is the outcome of teacher institutions and programs for teacher professional development, though it is difficult for teachers' efficacy to be internalized (Kaushal, 2017). Several researchers supported the positive impact of TPD on teacher quality (Bredeson, 2000, Darling-Hammond, Hyler, \& Gardner, 2017; Yue, Chen, Wang, \& Liu, 2017). According to Darling-Hammond, Hyler, \& Gardner (2017), a wellorganized TPD has various implications that contribute to school improvement. Engagement in active learning and fostering a cooperative working environment to be operational for supporting school reform for better teacher practice and school improvement are examples that can be mentioned. Wood, Petocz, \& Reid, (2012) stated the complexity of identifying effective professional development approaches. However, the authors underlined the significance of reflection for enhancing professionalism as instructors. In turn, this professional learning develops being responsive for 21 st-century student learning demands and as a lesson for policymakers (Darling-Hammond, Hyler, \& Gardner, 2017; Chen, 2020). A study by De Vries, van de Grift, \& Jansen, (2014) found a positive relationship between more teachers' participation in CPD and firm beliefs for student-oriented strategies that influence learning decisions. Carefully planned, well applied and sustained programs for faculty development fosters the perception of teaching as an enduring process and magnifies the significance of faculty continuous learning (Brancato, 2003).

Affouneh, Salha \& Habayeb (2014) indicated that TPD enhancements' impact could be seen on three levels - personal, institutional and national. Each trained teacher gained significantly from the lessons learned through group discussion, practices, and self-reflections at a personal level. At an institutional level, it is through leading the faculty, serving on university committees, directing centers and leading programs. Thus, the institutional impact of the TPD is both on the universities and the schools with which it works. Similarly, PD is a process of continuous learning. Improving faculty members' skills and knowledge leads to quality education (Chen, 2018), as faculty members are empowered to be alert for their responsibilities for improving teaching and learning (Brancato, 2003).

In the same vein of TPD contribution for school improvement, a study by Ghamrawi (2013) revealed that teachers take part in leading PD program nurtures pool for potential teacher leadership that make them more responsible and productive. Besides, OECD (2011) advocated the role of professional development as a tool for lifting the proficiency of teachers. Likewise, several researchers stated that PD decreases retention problems (Ingersoll \& May, 2012; Mertler, 2016). TPD enhances the success of education in addition to enriching knowledge and skill, and also elevates the morale and motivation of teachers (Yue, Chen, Wang, \& Liu, 2017).

\subsection{Challenges of TPD}

Teacher development programs are essential for the competitiveness of teachers in higher education institutes due to the rapid advancement in the field of education (Peng et al., 2014). Birney et al. (2014) stated that TPD programs largely affect the competencies of teachers. These competencies play a vital role in enabling effective learning outcomes in higher education (Armour \& Makopoulou, 2012). Therefore, since the last two decades, professionals are emphasizing the significance of TPD in higher education (Gast, Schildkamp \& Veen, 2017). Elci \& Yaratan (2012) stated that teachers in higher education institutes are responsible for creating a learning environment in the organization, so they have to develop themselves by improving their professional teaching and learning skills.

Concerning the nature of TPD, issue of funding and inadequate time are some of the challenges faced simultaneously (Kaushal, 2017). That is equally supported by research findings in European countries that recommend a new financing approach for TPD programs (Lipowski et al., 2011; Zhang, Shi, \& Lin, 2020). Lack of appropriate training in teaching for faculties in India's higher institutions (British Council, 2014), balancing time for research activities and teaching for Australian tertiary mathematics teachers (Wood,.et al,2011), the need to improve governance and management in England (Sarker, Davis, \& Tiropanis, 2010), motivating teachers through organized incentive systems as well as the need for more organized training programs in Hungary (Lipowskiet al., 2011) and identifying the model of professional development and invalid method of training programs in China (Yue, Chen, Wang, \& Liu, 2017) can be mentioned. In addition, a large population of teachers lamented on the inadequacy of supportive resources and geographical location as challenges that 
adversely affects TPD programs in Indonesia (Widodo, A., \& Riandi, 2013). The same authors identified a vertical (topdown) approach to TPD programs (a situation whereby subjects, approaches, and schedules have been predetermined) as having a negative impact on the successful implementation of TPD. Unplanned provision of TPD without considering teachers' needs was also found as a barrier (Zhang, Shi, \& Lin, 2020). The study reveals that TPD needs are different as veteran teachers demand the utilization of new technologies for teaching and learning, whereas new teachers reported high-level needs regarding subject knowledge.

Beside the internal demand of self-improvement, external pressure on institutions to find ways to improve the quality and effectiveness of teaching pose a great challenge for the institutions (Elci and Yaratan, 2012). Moreover, several factors from both the organizational level and task level create challenges for the effectiveness of PD programs (Evers et al., 2011). Wei, Darling-Hammond, \& Adamson, (2010) stated that PD programs in an educational institute are greatly affected by learning climate, team style; leadership, social support from immediate supervisor, and social support from close colleagues as well as task factors, i.e., work pressure, emotional demands and autonomy. These factors play a vital role in the successful implementation of PD programs for teachers (Iluz et al., 2012).

\section{Methodology}

The researchers adopted a case study design that employs a qualitative approach. To ensure anonymity, all participants were ascribed pseudonyms. Qualitative method allows the researchers to explore the subject of interest and acquire a detailed understanding of the phenomenon of interest (Creswell, 2018), and a case study research allows the authors to look at the phenomenon in context (Farquhar, 2012).

\subsection{Sampling, Interview Protocol, and Qualitative Procedures}

The purposive sampling technique was used to recruit the two deans of the faculty of the selected university. Each of the two deans were interviewed by the researchers. The duration of the interview ranged from 20-30 minutes. All interviews were recorded and transcribed verbatim. The participants responded to questions on an interview guide self-designed by the researchers and reviewed by a researcher in the field of qualitative research. The interview guide was structured based on standards in extant literature and the relevant reviewed literature. This included a list of semi-structured and openended questions to elicit response from the participants on how they are able to improve the faculty of the selected university through TPD. In qualitative research, Adarkwah \& Zeyuan (2020) \& Esterberg (2002) recommends researchers to probe for further insight into the research questions. Probing questions were used to gain in-depth meaning of an answer where necessary.

\subsection{Data Collection and Analysis}

To get access to the school leaders, a professor of the selected university was contacted. First, a letter of invitation was sent to the each of the two deans detailing the topic and aims of the study. The school leaders were asked to give a verbal account of the questions asked in the study. All the interviews were conducted in English and audiotaped after consent was gained. The transcribed audiotaped interviews were sent back to the school leaders for checking before analysis was initiated. This approach helps to do away with errors of transcription and ensure that the study provides credible and authentic results (Guba \& Lincoln, 1989). Each of the authors reviewed the complete transcribed data to identify emerging themes using a grounded theory approach (Eaves, 2001; Glaser, 1978; Strauss \& Corbin, 1990). The grounded theory approach to data analysis help in categorizing major themes that emerged from the data set through multiple reading and by identifying relationships and patterns. The authors met to review the emergent themes and refine them and ascribe codes. Similar themes were coded together using line analysis to organize the interviews according to their perceived importance to each of the three research questions (Chenail, 2012). Themes were validated by anecdotal interviews with some teachers in the faculty of Education of the case university. The analytical tool used for the coding of themes was the MAXQDA software.

\section{Results and Discussion}

The case study of TPD in the faculty of this selected university reveals the findings of the two deans' support for TPD, the role TPD has played in enhancing the development of the faculty, and the TPD-related challenges encountered. Overall, analysis of the statements made by the deans reveals that amidst other factors known to promote faculty development, the leaders of the faculty have targeted TPD as its prime factor. Sound policies are implemented, and a future plan is drafted to ensure TPD-related activities are organized to improve teacher pedagogical and research capabilities. The accounts from the deans indicate how TPD has increased research productivity and job performance. The deans reported few challenges which they have encountered along the way. Three themes corresponding to the research questions emerged from the analysis. The three subsections below present the accounts of the two deans on TPD activities in this faculty and how it relates to prior findings in literature. 
Table 1. Themes and sub-themes of interview responses

\begin{tabular}{|c|c|}
\hline Themes & Sub-themes \\
\hline \multirow[t]{7}{*}{ Leadership Support } & * Policies and Principles \\
\hline & Liaising with other educational bodies \\
\hline & * Mentorship \& Identifying common interest \\
\hline & * Academic Conferences \\
\hline & * Round-Table Discussions \\
\hline & * Motivational Strategies \\
\hline & 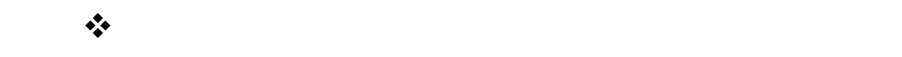 \\
\hline \multirow[t]{4}{*}{ TPD Role } & * Research Productivity \& Curriculum design \\
\hline & * Job Performance and Student Academic Achievement \\
\hline & * Faculty Development \\
\hline & $*$ \\
\hline \multirow[t]{3}{*}{ Challenges } & * Evaluation \\
\hline & * Conflict with Time \\
\hline & * Family Pressure and Financial Constraints \\
\hline
\end{tabular}

\section{Leadership Support}

Policies and Principles: According to the two deans, sound policies and principles are the bedrock for their TPD programs. Lack of direction and policies for teachers can hinder their PD (Lim, Juliana, \& Liang, 2020). The first step in implementing a sustainable TPD is to develop appropriate policies for it (Misra, 2018). Favorable policies for TPD facilitates the engagement of teachers in PD programs (West \& Bautista, 2020). The authors mentioned that the way teachers interact with and materially profits from PD programs is influenced by policies that provide them with access. Making and implementing policies that are underpinned by the mission of TPD aids in sustaining PD programs for faculty growth and development.

I think in the last five years, the university highlighted the policy of the TPD of young faculties. At the Faculty of Education, we have the system to help the young faculties to improve their research skills. Every semester we have about five to eight activities for the young faculties; how to design a research, how to improve the writing skills for their research and at the same time we established a platform for young faculties where we invite an editor of a journal to come and give tutorial for the young professors [Dean A].

The university has its own concrete principles and policies to support the faculty staff on how to conduct their research and engage in other TPD activities. Each teacher can therefore apply for a project from the government and will receive support from the faculty. Some special policies are made purposely to support the economic issues relating to the TPD activities [Dean B].

Liaising with other educational bodies: Lim et al. (2020) mentioned that local government, school leaders, and teachers all play a crucial role in supporting the professional learning of teachers. These key stakeholders in education should find a common ground on how TPD programs are organized and how it can be tailored to the needs of the teachers and the mission of the faculty/university. Also, universities can partner with other schools to provide quality PD for teachers (Sandholtz, 2002).

In China, the universities are very different. Our university belongs to the National Education Department. They also support the university to do some buying for the TPD activities. They have leaders and also experts from the government who prompt the faculty to do something. We are just workers here, working with the National Education Department and Government symbolizes unity. Myself and my other colleague all work together. This is a top-down approach. They will list projects we can apply for [Dean B].

Through the Ministry of Education, the university has built a center for teacher training. And I remember five years ago the new teachers will, all the new teachers will come for one-month training before they get the certificate to become the teacher of the university. They will take the class to study education and psychology theory and accept teacher training activities for one month in the summer before September. In September, they will go to different universities that allow 
them to take part in some lectures, seminars, and micro-teaching to help them improve their teaching skills to be able to survive in the classroom [Dean A].

Mentorship \& Identifying common interest: Mentoring as part of the PD of teachers has been identified as an integral factor to increase teacher performance, commitment, productivity, and smoothly integrate teachers into a new program (Irby, Lynch, Boswell, \& Hewitt, 2017). Gjedia \& Gardinier (2018) opined that mentoring contributes to the PD of teachers by enhancing the pedagogical knowledge of teachers, make them efficacious, and increase their satisfaction. These mentors are experts in a specific field who can co-teach with teachers and offer them guidance. In TPD, teacher collaboration can be enhanced by the formulation of teacher teams during activities (Gas, Schildkamp, \& van der Veen, 2017). For example, in relating to identifying teachers' common interests, teachers teaching the same subject are permitted to have one day off every week to engage in TPD sessions together in Indonesia (Widodo \& Riandi, 2013).

And also at faculty level we also give many help to the young teachers, if they don't have the 5-year experience, we will give a tutor to the young faculties. For example, I am the tutor for one young faculty [means young teacher]. He will come to my class to observe my teaching for one semester, and I will give him advice on how to organize the class, how to help the class, this is at the faculty level [Dean A].

We also assume that some teachers have some things in common, so we organize an academic activity to identify those who have similar research interests, and they are grouped together. The grouped teachers can engage or apply for the same project, such as an international conference, since they have similar research interests. Also, we invite foreign experts and also from China to speak to the teachers [Dean B].

Academic Conferences: Teacher participation in international professional conferences as part of their PD is associated with improvement in students' achievement and also gives them the opportunity to interact and present on their research (Akiba \& Liang, 2016). Prior literature has also revealed that brief workshops and conferences help in fostering teacher awareness and interest in improving their skills and knowledge (Boyle, Lamprianou, \& Boyle, 2005). Making conference presentations and attention seminars organized by the university faculty all are means to provide in-service training to teachers (Sandholtz, 2002). The deans reported that they give opportunities and monetary support for young teachers to participate in international conferences. Jointly attending academic conferences also fosters teacher collaboration (McComb \& Eather, 2017).

The university have a special budget for the teacher training, to provide some support for the young faculty. For example, if the young faculty goes abroad to take part in an international conference, the university can pay for their transportation and accommodation. Every year, one international travelling. This is the support from the faculty [Dean A].

The economic situation of the university enables us to support the young faculties to attend international conferences. Such conferences will open their minds and will help them to publish their research. They will attract academic researchers to talk about their research questions. So we give the faculties a chance for them to communicate more academic researchers through this [Dean B].

Round-Table Discussions: The social dimension of TPD calls for a restructuring of school norms and traditions such as from privacy and individualism to collaboration, collegiality, and empowerment (Tran, et al., 2020). West \& Bautista (2020) revealed that Singapore initiated "Thinking Schools, Learning Nation" and a new model called "Teacher Growth Model" to serve as a replacement of the traditional notion that teachers as technicians by conceptualizing them as reflective professionals. This new approach to PD encouraged teachers to take control of their own PD. In our research context, the round-table discussions are geared towards achieving this goal. Faculty leaders meet with teachers on how to improve the teaching, learning, and research by designing a new culture for the faculty that is suitable for TPD activities.

The Faculty of Education has English taught program with 36 teachers, of which most of them are young. Every semester we talk and discuss for about two to three times on how to improve their teaching and how to publish a paper in an English journal [Dean A].

Sometimes we inspire the faculties. We randomly organize small meetings to talk about TPD activities and to understand one another. The faculties are given the room to interchange ideas. For example, how to change the traditional school culture to construct a new culture that will help them publish timely [Dean B].

Motivational Strategies: He \& Ho (2017) highlighted how the use of motivational strategies are essential to stimulate teachers to engage in TPD activities and ensure improved performance. Teachers are rewarded based on their work characteristics and their individual needs. Financial incentive is a popular approach to promote PD activities (Zhang, Shi, \& Lin, 2019). The authors further cited that the lack of motivational strategies can demotivate teachers to accept and engage in PD activities.

There is no punishment but only encouragement for teachers. If they make more contributions to the faculty, they can get more income or payment. For example, if they publish more papers, that means you made constructive contributions to 
the faculty, so we will give them the reward for that. And if you have more teaching, then you get more payment for the teaching [Dean A].

\section{TPD Role}

Research Productivity \& Curriculum design: In HE context, increased research can be a burden (Kálmán, Tynjälä, \& Skaniakos, 2020). One effective way to improve the research productivity of teachers is to engage them in PD activities. According to Darling-Hammond (2010), schools that engage in PD are teaching hospitals, which provide an avenue for teachers and researchers to meet together in a non-hierarchical level where teachers are guided in their practice. The accounts from the two deans indicate that they pay close attention to the research productivity of teachers at the faculty. The TPD activities have increased teachers' academic writing and research methodology to publish in reputable international journals. Anecdotally, one dean revealed how the faculty is assessed based on their research productivity and the quality of the journal where they publish their work. Additionally, because the school admits international students in English-taught programs, teachers who are close to students aid in structuring a curriculum and their contribution over the past years has been facilitated by TPD. The TPD programs help in the internalization of new curricula.

Our TPD activities, such as our English-taught programs, enable the young faculties to publish in international journals. The English-taught program is not only for teaching purposes. We have to develop a curriculum which would be published. So teachers are encouraged to take ideas from their class. Such TPD activities encourage teachers to teach based on their research projects. Thus, combining teaching and research together [Dean A].

Job Performance and Student Academic Achievement: A large body of research have revealed that TPD activities are efficacious in enhancing teaching quality, job performance, and the academic achievement of students (Tran, et al., 2020; Yin, Dooley, \& Mu, 2019). Teacher effectiveness can be enhanced by PD by providing teachers with continuous improvement required for ensuring successful learning outcomes of students (Soine \& Lumpe, 2014). Koh (2017) emphasized that one of the outcomes of TPD programs is student academic achievement. Thus, when evaluating the effect of TPD programs, the learning outcomes of students are also taken into consideration. Yin et al. (2019) add that improvement in student learning is one of the most significant impacts of TPD on education.

Because of the TPD activities, there is a competition to achieve more. Most of the young faculties work very hard because many of them get a job here after their post-doc, that means they are very competitive in the research. They have very clear objectives by themselves [Dean A].

We give some of the young faculties the chance to be the supervisor for the undergrad students. So every year, they can have two or three undergrad students to help them to know more about the education area. If they become the supervisor of the master's students, they guide the master's students in their academic work [Dean B].

Faculty Development: The deans recounted how through the TPD sessions, they communicate the mission and vision of the faculty to the teachers. The PD of teachers gives them more responsibility, whose accomplishment ultimately leads to the development of the faculty. Since teachers are motivated through incentives and other supportive mechanisms, they are eager to improve their skills and knowledge by engaging in more PD programs. This translates into increased performance at the faculty level.

We established a new office we call the first-class education office. And we invite the twelve young faculties on behalf of different subjects such as higher education, comparative education, moral education, everyone on behalf of one subject, so they will do a lot of things for the faculty, not only for themselves. I think if they have more tasks, they will think about development from the perspective of the faculty, not only to think about themselves. If they focus more on the faculty development, I think they can have a broader view of the future. So that's the things we are doing [Dean A].

\section{Challenges}

Despite the all the positive impacts TPD has improved the faculty of this case study, it is not free from challenges. There are still a few challenges to totally overcome if the faculty wants to maintain its standard and hold on to its reputation. These challenges are common in both school and HE contexts as far as TPD s concerned. The interviews suggest that the deans plan to find solutions to these identified challenges.

Evaluation: Evaluation and supervision are also integral aspect of TPD (Tran, et al., 2020). The variability in the quality of PD for teachers makes evaluation a critical component, and this has been advocated for by educators and researchers across the globe (McChesney \& Aldridge, 2018). PD should be scrutinized and judged based on its impact on teacher behavior and the academic outcomes of students (Soine \& Lumpe, 2014). However, the authors reported that tools for evaluating PD are scarce and also costly. In our interview with the two deans, it was revealed that the faculty are faced with a similar problem. When there is a lack of evaluation, teachers lack the incentive to take PD programs seriously (Svendsen, 2020). Despite the fact that they have structured a clear policy for PD activities and the obvious positive impact of PD on the growth and development of the faculty, they find it difficult to assess individual teachers. 
We need a clearer plan for the TPD for young faculties. We have the practice, but we don't have a clear plan, especially about evaluation. How we will assess the young faculties. Maybe we will ask the young faculty what about their three years plan and we will have the assessment for them, maybe this is more efficient [Dean A].

Conflict with Time: Time and distance are major challenges for the implementation of TPD programs (Zhang, Shi, \& Lin, 2020). The authors mentioned that some teachers in the US teach for long hours, which serve as a barrier for them to engage in PD programs. When teacher embarks on their routine activities, there is less time for collaborative PD. One strategy the dean mentioned was prioritizing TPD above routine tasks.

Time is very important. You know we all in the university have many things to do. Sometimes we may not have an activity because of time constraints. We need to make some rules to do first things first [Dean B].

Family Pressure and Financial Constraints: Zhang, Shi, \& Lin, 2020 mentioned that some of the contextual factors that affect TPD are family commitment and financial considerations. In China, the payment of teacher salaries differs across regions. In our case study, the location of the university contributes to the low salary of teachers as compared to their counterparts in other regions. Leaders at the university and faculty level try to compensate for this loss by the provision of incentives and other supportive strategies.

Because of the location of our university we don't give the young faculties much income. The other thing is, the young faculties if they finish their post-doc studies, they face many kinds of pressure, not only for the academic, not only for the teaching but from the family, to pay for the apartment, to raise the kids, I always remind the young faculties don't forget your career although the family is also important [Dean A].

The only challenge is we have very limited resources. Maybe in the future, we can have a budget that will help the young faculties. The young faculties they have a lot of pressure from their families. Their salary is low, maybe because they are young [Dean B].

\section{Conclusion}

Despite the integral role TPD plays in teaching and learning, successful TPD implementation and sustainability is difficult to attain. Also, research studies on the subject matter have geared towards the school context, with fewer studies in the HE context. There is less research on the PD of teachers in China published in English for the perusal of researchers across the globe. The study adds to the limited studies on TPD in HE by exploring how it fosters faculty development through leadership practices. Specifically, it gives a detailed account of how this selected faculty has dramatically risen in the limelight of education in China. Two deans responsible for TPD programs in the selected faculty of the university were interviewed to gain insights to the research questions (what leadership support was provided for the implementation of TPD? what role has TPD played in facilitating faculty development? and what are the perceived challenges associated with TPD in higher education?). Findings indicate that enacting sound policies and principles for TPD is the first step towards its realization. Such policies lay a framework and a guideline for organizing TPD activities. The various ways the deans supported TPD were through mentorship, open discussion sessions to deliberate on TPD issues, promoting collaboration by identifying teachers' interests and grouping them, providing opportunities and monetary support for teachers to attend international conferences, and financial incentives and promotion as a motivational strategy. Strikingly, these leadership practices have proved to be effective despite the hierarchical structure of TPD in China (He \& Ho, 2017). In the western world, it is a major challenge for professional learning communities, which includes TPD to thrive while adhering to a bureaucratic model (Chen, 2020). However, the context is different in China. Chen (2020) reports that the establishment of Teaching Research Groups (TGRs) as part of the PD of teachers has had a positive impact in China and is well supported by the Chinese culture. Thus, despite the hierarchical approach to TPD in Chinese universities, there is less tension between the government, school administration, and teachers because of the Chinese tradition of collaboration, collectivism, and personal connections. Chen added that teachers are willing to devote time to PD activities because they are accustomed to the practice of collaboration between these stakeholders in education. According to the deans, the TPD in this faculty has increased the research productivity of teachers and have made them efficacious in designing a curriculum for the faculty that factors the interests and academic needs of international students. Because teacher skills and knowledge have increased as a result of the PD, this has translated into improved job performances. Ultimately, students' academic achievement in terms of their engagement in the classroom, grades, and graduation rates have improved over time. Thus, when TPD is well implemented and supervised, it leads to school effectiveness and improvement (Affouneh, Salha \& Habayeb, 2014). Yet, the PD activities in this selected faculty are still fraught with some challenges such as time/distance, evaluation mechanism of the PD activities, and external pressures such as from family.

\section{Limitations}

A great limitation of the study is the restriction of the research to one university. Also, not all stakeholders responsible for the TPD program in the selected university were interviewed. The current study only accounts for the provider's lens on 
the TPD program in the case university. However, the in-depth inquiry sheds light on how the faculty of education of this university can serve as a model to peer universities in China and beyond. The present study lays a foundation for further inquiry on leadership practices and PD of teachers.

\section{Recommendations}

To mitigate challenges identified in this paper, information on TPD programs should be communicated to all players involved in advance for them to be able to plan their schedules. Summative assessments should be performed on all organized TPD activities within the year. Summative assessment has proven to have a positive influence on teaching and learning, and an effective tool for administrators to ensure school improvement (Adarkwah, 2021). Administrators of the universities should perform an annual survey or interviews to seek TPD designers and teachers' perspectives on TPD outcomes to identify barriers to its effectiveness. Course assessment is also needed to identify how TPD is implemented in the classrooms and challenges with effective implementation. Moreover, TPD models at the national level should be adopted in a manner that it suitable for the university context. Since China has different universities with distinct contexts, a generalized TPD model may not achieve a greater result in comparison to when it is contextualized. Teachers should also formulate goals aimed at increasing their technical knowledge and competence to transform their students and ultimately, their universities. By setting concrete objectives, organizers of TPD programs will be privy to activities tailored to the needs of the teachers to increase their self-efficacy and pedagogical content knowledge. All formal and informal policies should be aimed at providing more opportunities for teachers to access PD, which is of high quality and is also transformative in nature. The current study serves as a roadmap for future studies on TPD in China and beyond. The authors recommend that further researchers conduct a thorough investigation on TPD in Chinese-based settings where TPD implementation has not been totally successful as opposed to the case university. Future researchers can perform a quantitative study using large samples of school leaders and teachers engaged in PD in diverse universities or adopt a sophisticated design such as mixed-methods to ascertain different experiences of the various universities. Triangulation of data will increase the dependability, credibility, transferability, and confirmability of the research.

\section{References}

Abdul Razzak, N. (2013). The effectiveness of a university-based professional development program in developing Bahraini school leaders' management and leadership competencies of implementing effective school-wide professional development and ICT integration. Professional development in Education, 39(5), 732-753. https://doi.org/abs/10.1080/19415257.2012.759127

Adarkwah, M. A. (2021). The power of assessment feedback in teaching and learning: a narrative review and synthesis of the literature. SN Social Sciences, 1(75), 1-44. doi:10.1007/s43545-021-00086-w

Adarkwah, M. A., \& Zeyuan, Y. (2020). Perceptions of the effect of an EAP course on English self-efficacy and English proficiency: Voices of international students in China. World Journal of English Language, 10(2), 1-17. doi:10.5430/wjel.v 10 n 2 p 1

Affouneh, S., Salha, S., \&Habayeb, A. (2014). Evaluation of An-Najah National University experience in enhancing Electronic Management System (Moodle) in the training of in-service teachers' program. Hebron University Journal for Research, 9(2), 95-117.

Akiba, M., \& Liang, G. (2016). Effects of teacher professional learning activities on student achievement growth. The Journal of Educational Research, 109(1), 99-110. https://doi.org/10.1080/00220671.2014.924470

Antil, N. (2017). Professional Development of Teachers in Higher Education. Research Journal of Humanities and Social Sciences, 8(3), 311-315.

Armour K. M., \&Makopoulou, K. (2012). Great expectations: Teacher learning in a national professional development program. Teaching and Teacher Education, 28(3), 336-346. https://doi.org/10.1016/j.tate.2011.10.006

Avidov-Ungar, O., \&Ezran, E. (2018). The Hashkafa program as a framework for the professional development of teachers: The perceptions of principals. Leadership and Policy in Schools, 19(2), 1-20. https://doi.org/10.1080/15700763.2018.1513157

Badri, M., Alnuaimi, A., Mohaidat, J., Yang, G., \&Rashedi, A. A. (2016). Perception of teachers' professional development needs, impacts, and barriers: The Abu Dhabi case. SAGE Open, 1-15. https://doi.org/10.1177/2158244016662901

Birney, D. P., Beckmann, J. F., \& Wood, R. E. (2012). Precursors to the development of flexible expertise: Meta-cognitive self-evaluations as antecedences and consequences in adult learning. Learning and Individual Differences, 22, 563574. https://doi.org/10.1016/j.lindif.2012.07.001

Boyle, B., Lamprianou, I., \& Boyle, T. (2005). A longitudinal study of teacher change: What makes professional 
development effective? Report of the second year of the study. School Effectiveness and School Improvement, 16(1), 1-27. https://doi.org/10.1080/09243450500114819

Brancato, V. C. (2003). Professional development in higher education. New directions for adult and continuing education, 2003(98), 59-66. https://doi.org/10.1002/ace.100

Bredeson, P. V. (2000). The school principal's role in teacher professional development. Journal of In-Service Education, 26(2), 38-401. https://doi.org/10.1080/13674580000200114

British Council. (2014). Understanding India: The future of higher education and opportunities for international cooperation. Retrieved on https://www.britishcouncil.in/sites/default/files/understanding_india.pdf, 26(5), 15

Chen, C. C. (2018). Facilitation of teachers' professional development through principals' instructional supervision and teachers' knowledge-management behaviors. Contemporary Pedagogies in Teacher Education and Development, 51. https://doi.org/10.5772/intechopen.77978

Chen, L. (2020). A historical review of professional learning communities in China (1949-2019): some implications for collaborative teacher professional development. Asia Pacific Journal of Education, 1-13. https://doi.org/10.1080/02188791.2020.1717439

Chenail, R. J. (2012). Conducting qualitative data analysis: Reading line-by-line, but analyzing by meaningful qualitative units. The Qualitative Report, 17(1), 267-269. Retrieved from http://nsuworks.nova.edu/tqr/vol17/iss1/12

Cockpim, J., \&Somprach, K. (2019). Learning leadership of school administrators and teaching behavior affecting the effectiveness of teacher professional development: hierarchical linear model. The Turkish Online Journal of Educational Technology, 18(2), 52-57.

Creswell, J. W. (2018). Research design: qualitative, quantitative, and mixed methods approaches (Fifth edition ed.). Los Angeles: SAGE.

Darling-Hammond, L. (2010). Teacher education and the American future. Journal of Teacher Education, 61(1-2), 35-47. https://doi.org/10.1177/0022487109348024

Darling-Hammond, L., Hyler, M. E., Gardner, M., \& Espinoza, D. (2017). Effective teacher professional development. Palo Alto, CA: Learning Policy Institute.

De Vries, S., van de Grift, W. J., \& Jansen, E. P. (2014). How teachers' beliefs about learning and teaching relate to their continuing professional development. Teachers and Teaching, 20(3), 338-357. https://doi.org/10.1080/13540602.2013.848521

Didion, L., Toste, J. R., \&Filderman, M. J. (2019). Teacher professional development and student reading achievement: A meta-analytic review of the effects. Journal of Research on Educational Effectiveness, 13(1), 29-66. https://doi.org/10.1080/19345747.2019.1670884

Eaves, Y. D. (2001). A synthesis technique for grounded theory data analysis. $J$ Adv Nurs, 35(5), 654-663. https://doi.org/10.1046/j.1365-2648.2001.01897.x.

Elci, A., \& Yaratan, H. (2012). Needs for professional development in teaching and learning in an international university. Eurasian Journal of Educational Research, 12(49A), 47-65.

Elton, L. (2009). Continuing professional development in higher education: The role of the scholarship of teaching and learning. Arts and Humanities in Higher Education, 8(3), 247-258. https://doi.org/10.20429/ijsotl.2009.030128

Esterberg, K. G. (2002). Qualitative Methods in Social Research. Boston, MA: McGraw-Hill.

Evers, A. T., van der Heijden, B. I., Kreijns, K., \& Gerrichhauzen, J. T. (2011). Organisational factors and teachers' professional development in Dutch secondary schools. Journal of European Industrial Training, 35(1), 2444. https://doi.org/10.1108/03090591111095727

Evers, A. T., Van der Heijden, I. J., \&Kreijns, K. (2016). Organisational and task factors influencing teachers' professional development at work. European Journal of Training and Development, 40(1), 36-55. https://doi.org/10.1108/EJTD03-2015-0023

Falkner, K., Vivian, R., \& Williams, S.-A. (2018). An ecosystem approach to teacher professional development within computer science. Computer Science Education, 28(4), 303-344. https://doi.org/10.1080/08993408.2018.1522858

Fancera, S. F. (2019). School leadership for professional development: The role of social media and networks. Professional Development in Education, 1-14. https://doi.org/10.1080/19415257.2019.1629615

Farquhar, J. D. (2012). What is Case Study Research? In J. D. Farquhar, Case study research for business (pp. 3-14). 
London: SAGE Publications. https://doi.org/10.4135/9781446287910.n2

Gast, I., Schildkamp, K., \& van der Veen, J. T. (2017). Team-Based professional development interventions in higher education: A systematic review. Review of Educational Research, 87(4), 736-767. https://doi.org/10.3102/0034654317704306

Geijsel, F. P., Sleegers, P. J., Stoel, R. D., \& Krüger, M., L. (2009). The effect of teacher psychological and school organizational and leadership factors on teachers' professional learning in Dutch schools. The elementary school journal, 109(4), 406-427. https://doi.org/10.1086/593940

Ghamrawi, N. (2013). Teachers helping teachers: A professional development model that promotes teacher leadership. International Education Studies, 6(4), 171-182. https://doi.org/10.5539/ies.v6n4p171

Glaser, B. G. (1978). Theoretical Sensitivity Advances in the Methodology of Grounded Theory. Mill Valley, CA: The Sociology Press.

Guba, E., \& Lincoln, Y. S. (1989). Fourth generation evaluation. Beverly Hills, CA: Sage.

Guo, L. (2012). New curriculum reform in China and its impact on teachers. Canadian and International Education, 41(2), 87-105. https://doi.org/10.5206/cie-eci.v41i2.9205

Hairon, S., \&Dimmock, C. (2012). Singapore schools and professional learning communities: Teacher professional development and school leadership in an Asian hierarchical system. Educational Review, 64(4), 405-424. https://doi.org/10.1080/00131911.2011.625111

Hallinger, P., \& Liu, S. (2017). Leadership and teacher learning in urban and rural schools in China: Meeting the dual challenges of equity and effectiveness. International Journal of Educational Development, 51, 163-173. https://doi.org/10.1016/j.ijedudev.2016.10.001

Hallinger, P., Liu, S., \&Piyaman, P. (2017). Does principal leadership make a difference in teacher professional learning? A comparative study China and Thailand. Compare: A Journal of Comparative and International Education, 49(3), 341-357. d https://doi.org/10.1080/03057925.2017.1407237

Hanno, E. C., \& Gonzalez, K. E. (2019). The effects of teacher professional development on children's attendance in preschool. Journal of Research on Educational Effectiveness, 13(1), 3-28. https://doi.org/10.1080/19345747.2019.1634170

He, P., \& Ho, D. (2017). Leadership for school-based teacher professional development: The experience of a Chinese preschool. International Journal of Leadership in Education, 20(6), 717-732. https://doi.org/10.1080/13603124.2016.1180431

Iluz, S., Michalsky, T., \&Kramarski, B. (2012). Developing and accessing the Life Challenges Teacher Inventory for teachers' professional growth. Studies in Educational Evaluation, 38(2), 44-54. https://doi.org/10.1016/j.stueduc.2012.05.002

Ingersoll, R. M., \& May, H. (2012). The magnitude, destinations, and determinants of mathematics and science teacher turnover. Educational Evaluation and Policy Analysis, 34(4), 435-464. https://doi.org/10.3102/0162373712454326

Irby, B. J., Lynch, J., Boswell, J., \& Hewitt, K. K. (2017). Mentoring as professional development. Mentoring \& Tutoring: Partnership in Learning, 25(1), 1-4. https://doi.org/10.1080/13611267.2017.1312895

Ji, Z., \& Cao, Y. (2016). A prospective study on the application of MOOC in teacher professional development in China. Universal Journal of Educational Research, 4(9), 2061-2067. https://doi.org/10.13189/ujer.2016.040917

Kálmán, O., Tynjälä, P., \& Skaniakos, T. (2020). Patterns of university teachers' approaches to teaching, professional development and perceived departmental cultures. Teaching in Higher Education, 25(5), 595-614. https://doi.org/10.1080/13562517.2019.1586667

Kaushal, S. (2017). Professional Development of Teachers in Higher Education in India. Amity International Journal of Teacher Education (AIJTE),3(1).

Kayange, J. J., \& Msiska, M. (2016). Teacher education in China: training teachers for the 21st century. The Online Journal of New Horizons in Education, 6(4), 204-210.

Ke, Z., Yin, H., \& Huang, S. (2019). Teacher participation in school-based professional development in China: does it matter for teacher efficacy and teaching strategies? Teachers and Teaching, 25(7), 821-836. https://doi.org/10.1080/13540602.2019.1662777

Keller, M. M., Neumann, K., \& Fischer, H. E. (2017). The impact of physics teachers' pedagogical content knowledge and motivation on students' achievement and interest. Journal of Research in Science Teaching, 586-614. 
https://doi.org/ 10.1002/tea.21378

Koh, J. L. (2017). TPACK design scaffolds for supporting teacher pedagogical change. Educational Technology Research and Development, 67, 577-595. https://doi.org/10.1007/s11423-018-9627-5

Lam, B. H. (2015). Teacher professional development in Hong Kong compared to anglosphere: The role of Confucian philosophy. Psychology, Society and Education, 7(3), 295-310. https://doi.org/10.25115/psye.v7i3.521

Li, L., Hallinger, P., \& Walker, A. (2015). Exploring the mediating effects of trust on principal leadership and teacher professional learning in Hong Kong primary schools. Educational Management Administration \& Leadership, 44(1), 1-23. https://doi.org/10.1177/1741143214558577

Lijuan, L., \& Hallinger, P. (2016). Communication as a mediator between principal leadership and teacher professional learning in Hong Kong primary schools. International Journal of Educational Reform, 25(2), 192-212. https://doi.org/10.1177/105678791602500205

Lim, C. P., Juliana, \& Liang, M. (2020). An activity theory approach toward teacher professional development at scale (TPD@Scale): A case study of a teacher learning center in Indonesia. Asia Pacific Education Review, 21, 525-538. https://doi.org/10.1007/s12564-020-09654-w

Lipowski, K., Jorde, D., Prenzel, M., \& Seidel, T. (2011). Expert views on the implementation of teacher professional development in European countries. Professional development in education,37(5), 685-700. https://doi.org/10.1080/19415257.2011.621968

Liu, S., \&Hallinger, P. (2018). Teacher development in rural China: how ineffective school leadership fails to make a difference. International Journal of Leadership in Education, 21(6), 633-650. https://doi.org/10.1080/13603124.2017.1294266

Martí, M. C., \& Ferrer, G. T. (2012). Exploring learners' practices and perceptions on the use of mobile portfolios as a methodological tool to assess learning in both formal and informal contexts. Procedia-Social and Behavioral Sciences, 46, 3182-3186. https://doi.org/10.1016/j.sbspro.2012.06.033

Matsumura, L. C., Sartoris, M., Bickel, D. D., \&Garnier, H. E. (2009). Leadership for literacy coaching: The principal's role in launching a new coaching program. Educational Administration Quarterly, 45(5), 655-693. https://doi.org/10.1177/0013161X09347341

McChesney, K., \& Aldridge, J. M. (2018). A review of practitioner-led evaluation of teacher professional development. Professional Development in Education, 45(2), 307-324. https://doi.org/10.1080/19415257.2018.1452782

McComb, V., \& Eather, N. (2017). Exploring the personal, social and occupational elements of teacher. Journal of Education and Training Studies, 5(12), 60-66. https://doi.org/10.11114/jets.v5i12.2794

Mertler, C. A. (2016). Should I stay or should I go? Understanding teacher motivation, job satisfaction, and perceptions of retention among Arizona teachers. International Research in Higher Education, 1(2), 34-45. https://doi.org/10.5430/irhe.v1n2p34

Misra, P. K. (2018). MOOCs for teacher professional development: Reflections and suggested actions. Open Praxis, 10(1), 67-77. https://doi.org/10.5944/openpraxis.10.1.780

Morris, J., \& Patterson, R. (2013, December 19). World-class education? Why New Zealand must strengthen its teaching profession. Retrieved from https://nzinitiative.org.nz/on

Mourão, L. (2018). The role of leadership in the professional development of subordinates. In S. D. Göker (Ed.), Leadership. https://doi.org/10.5772/intechopen.76056

Nappi, J. S. (2014). The teacher leader: Improving schools by building social capital through shared leadership. Delta Kappa Gamma Bulletin, 80(4), 29-34.

Noe, R. A., Tews, M. J., \&Marand, A. D. (2013). Individual differences and informal learning in the workplace. Journal of vocational behavior, 83(3), 327-335. https://doi.org/10.1016/j.jvb.2013.06.009

OECD. (2011). Teachers Matter: Attracting, Developing and Retaining Effective Teachers. Pointers for Policy Development.

OECD. (2016). Education in China: A snapshot. Retrieved on August, 9th 2018 from https://www.oecd.org/china/Education-in-China-a-snapshot.pdf

Öğretmen, O. Y., Gelişimine, M., \&Algıları, K. İ. (2020). Perceptions of school administrators on their contributions to teacher professional development. Journal of Theoretical Educational Science, 13(1), 7890. https://doi.org/10.30831/akukeg.541053 
Peng, W. J., McNess, E., Thomas, S., Wu, X. R., Zhang, C., Li, J. Z., \& Tian, H. S. (2014). Emerging perceptions of teacher quality and teacher development in China. International Journal of Educational Development, 34(1),77-89. https://doi.org/org/10.1016/j.ijedudev.2013.04.005

Robinson, V. M., Lloyd, C. A., \& Rowe, K. J. (2008). The Impact of Leadership on Student Outcomes: An Analysis of the Differential Effects of Leadership Types. Educational Administration Quarterly, 44(5), 635-674. https://doi.org/10.1177/0013161x08321509

Sandholtz, J. H. (2002). Inservice training or professional development: contrasting opportunities in a school/university partnership. Teaching and Teacher Education, 18, 815-830. https://doi.org/10.1016/S0742-051X(02)00045-8

Sarker, F., Davis, H., \& Tiropanis, T. (2010). A review of higher education challenges and data infrastructure responses. Conference: International Conference for Education Research and Innovation (ICERI2010)

Soine, K. M., \& Lumpe, A. (2014). Measuring characteristics of teacher professional development. Teacher Development: An international journal of teachers' professional development, 18(3), 303-333. https://doi.org/10.1080/13664530.2014.911775

Somprach, K., Tang, K. N., \&Popoonsak, P. (2017). The relationship between school leadership and professional learning communities in Thai basic education schools. Educational Research Policy and Practice, 16, 157175. https://doi.org/10.1007/s10671-016-9206-7

Stefani, L., \& Elton, L. (2002). Continuing professional development of academic teachers through self-initiated learning. Assessment \& Evaluation in Higher Education, 27(2), 117-129. https://doi.org/10.1080/02602930220128706

Strauss, A., \& Corbin, J. (1990). Basics of qualitative research: Grounded theory procedures and techniques. Thousand Oaks, CA: Sage Publications.

Svendsen, B. (2020). Inquiries into Teacher Professional Development—What Matters? Education, 140(3), 111-130.

Szeto, E. (2020). Influence of professional cultures and principal leadership effects on early-career teacher leadership development in Hong Kong schools. Professional Development in Education, 1-20. https://doi.org/10.1080/19415257.2020.1770837

Szetoa, E., Sin, K., \& Leung, G. (2020). A cross-school PLC: how could teacher professional development of robot-based pedagogies for all students build a social-justice school? Professional Development in Education, 116. https://doi.org/10.1080/19415257.2020.1787201

Tickle, B. R., Chang, M., \& Kim, S. (2011). Administrative support and its mediating effect on US public school teachers. Teaching and Teacher Education, 27(2), 342-349. https://doi.org/10.1016/j.tate.2010.09.002

Tran, H. N., Nguyen, D. C., Nguyen, G. V., Ho, T. N., Bui, Q. T. T., \& Hoang, N. H. (2020). Workplace conditions created by principals for their teachers' professional development in Vietnam. International Journal of Leadership in Education, 1-21. https://doi.org/10.1080/13603124.2019.1708472

Trent, J. (2020). Wither teacher professional development? The challenges of learning teaching and constructing identities across boundaries in China. Asia Pacific Journal of Education, 1-16. https://doi.org/10.1080/02188791.2020.1717438

Unirank. (2019, October 14). Southwest University. Retrieved from 4icu.org: https://www.4icu.org/reviews/924.htm

Wang, Y., Lavonen, J., \& Tirri, K. (2018). Aims for learning 21st century competencies in national primary science curricula in China and Finland. Eurasia Journal of Mathematics, Science \& Technology Education, 14(6), 20812095. https://doi.org/10.29333/ejmste/86363

Wei, R. C., Darling-Hammond, L., \& Adamson, F. (2010). Professional development in the United States: Trends and challenges (Vol. 28). Dallas, TX: National Staff Development Council.

West, J. J., \& Bautista, A. (2020). Greater than the sum of its parts: promoting systemness in music and arts teacher professional development. Arts Education Policy Review, 1-12. https://doi.org/10.1080/10632913.2020.1746716

Widodo, A., \&Riandi. (2013). Dual-mode teacher professional development: challenges and re-visioning future TPD in Indonesia. Teacher development, 17(3), 380-392. https://doi.org/10.1080/13664530.2013.813757

Wood, L. N., Petocz, P., \& Reid, A. (2012). How Can Professional Development Contribute to University Mathematics Teaching? In Becoming a Mathematician (pp. 147-162). Springer, Dordrecht.

Xin, X., \&Dervin, F. (2014). Dancing in fetters? Chinese principals' perceptions of the effects of Finnish training programs. Frontier Education of China, 9(2), 211-237. https://doi.org/10.3868/s110-003-014-0017-x 
Yager, S., \&Yager, R. (2011). Impact of school-based leadership teams for implementing a successful professional development initiative. International Journal of Educational Leadership Preparation, 6(1), 1-10. http://cnx.org/content/m37201/1.2/

Yan Zeng, \& Day, C. (2019). Collaborative teacher professional development in schools in England (UK) and Shanghai (China): cultures, contexts and tensions. Teachers and Teaching, 25(3), 379-397. https://doi.org/10.1080/13540602.2019.1593822

Yin, Y. M., Dooley, K., \& Mu, G. M. (2019). Why do graduates from prestigious universities choose to teach in disadvantaged schools? Lessons from an alternative teacher preparation program in China. Teaching and Teacher Education, 77, 378-387. https://doi.org/10.1016/j.tate.2018.10.011

Yue, J. J., Chen, G., Wang, Z. W., \& Liu, W. D. (2017). Factor analysis of teacher professional development in Chinese military medical universities. Journal of Biological Education, 51(1), 66-78. https://doi.org/org/10.1080/00219266.2016.1171793

Zhang, S., Shi, Q., \& Lin, E. (2020). Professional development needs, support, and barriers: TALIS US new and veteran teachers' perspectives. Professional Development in Education, 46(3), 440-453. https://doi.org/10.1080/19415257.2019.1614967

Zhao, J. (2010). School knowledge management framework and strategies: The new perspective on teacher professional development. Computers in Human Behavior, 26, 168-175. https://doi.org/10.1016/j.chb.2009.10.009

Zhao, Y. (2013). Professional learning community and college English teachers' professional development. Journal of Language Teaching and Research, 4(6), 1365-1370. https://doi.org/10.4304/jltr.4.6.1365-1370

Zhou, J. (2014). Teacher education changes in China: 1974-2014. Journal of Education for Teaching: International Research and Pedagogy, 40(5), 507-523. https://doi.org/10.1080/02607476.2014.956543

Zhu, X., \& Han, X. (2006). Reconstruction of the teacher education system in China. International Education Journal, $7(1), 66-73$.

Zusman, A. (2005). Challenges facing higher education in the twenty-first century. American higher education in the twenty-first century: Social, political, and economic challenges, 2, 115-160.

\section{Copyrights}

Copyright for this article is retained by the author(s), with first publication rights granted to the journal.

This is an open-access article distributed under the terms and conditions of the Creative Commons Attribution license which permits unrestricted use, distribution, and reproduction in any medium, provided the original work is properly cited. 